\title{
Temporal Change in Atmospheric Radiocesium during the First Seven Years after the Fukushima Dai-ich Nuclear Power Plant Accident
}

\author{
Tomohisa Abe ${ }^{*}$, Kazuya Yoshimura, Yukihisa Sanada
}

Remote Monitoring Research Group, Fukushima Environmental Monitoring Division, Collaborative Laboratories for Advaced Decomissioning Science, Japan Atomic Energy Agency, Fukushima, 975-0036, Japan

\section{ABSTRACT}

After the Fukushima Daiichi Nuclear Power Plant accident, the Nuclear Regulation Authority monitored the atmospheric radiocesium concentration as a national project to assess its temporal changes from August 2011 till November 2017. The concentration ranged from $10^{-1}$ to $10^{0} \mathrm{~Bq} \mathrm{~m}^{-3}$ during the first two years but from $10^{-5}$ to $10^{-1} \mathrm{~Bq} \mathrm{~m}^{-3}$ approximately seven years following the accident. Additionally, the resuspension factor $(R F)$ fell between $10^{-7}$ and $10^{-6} \mathrm{~m}^{-1}$ at the beginning of the third year but eventually declined to values between $10^{-11}$ and $10^{-7} \mathrm{~m}^{-1}$. To investigate the effect of anthropogenic activities on the temporal change in this parameter, we categorized the monitoring data into those from within and without the entry-restricted zone. The latter exhibited a higher rate of decrease in the $R F$, which agrees with the previously reported data on the time dependence of the air dose rate and suggests that anthropogenic activities promote environmental remediation and reduce atmospheric radiocesium. Finally, as the rate observed in this study exceeds that reported for the Chernobyl Nuclear Power Plant accident over the corresponding period, it warrants ongoing assessment based on current monitoring data.

Keywords: Atmospheric radiocesium, Resuspension factor, Fukushima Daiichi nuclear power plant accident, Time dependency

\section{OPEN ACCESS}

Received: November 25, 2020

Revised: February 3, 2021

Accepted: March 1, 2021

${ }^{*}$ Corresponding Author:
tomohisa.abe@jaea.go.jp

\section{Publisher:}

Taiwan Association for Aerosol Research

ISSN: $1680-8584$ print

ISSN: 2071-1409 online

(c) Copyright: The Author(s). This is an open access article distributed under the terms of the Creative Commons Attribution License (CC BY 4.0), which permits unrestricted use, distribution, and reproduction in any medium, provided the original author and source are cited.

\section{INTRODUCTION}

The severe accident that broke out at the Fukushima Daiichi Nuclear Power Plant (FDNPP) in March 2011 released a large amount of radiocesium into the atmosphere. Radiocesium is considered to be an important radioactive substance deposited on the ground after the accident in terms of radiation exposure due to its high level of release and long half-life $\left(2.06 \mathrm{y}\right.$ for ${ }^{134} \mathrm{Cs}$ and $30.17 \mathrm{y}$ for ${ }^{137} \mathrm{Cs}$ ) (WHO, 2012; Yoshimura et al., 2020). The exposure pathway in the contaminated area has been categorized into external and internal exposure (International Atomic Energy Agency (IAEA), 2013); the internal exposure mainly involves the inhalation of resuspended atmospheric aerosol, which is crucial for the retrospective assessment and prediction of the radiation risk. Therefore, the radiocesium activity and temporal changes in its atmospheric content need to be evaluated and understood to estimate the effects of inhalation exposure.

Following the accident at the Chernobyl Nuclear Power Plant (CNPP), radioactivity in atmospheric aerosol has been extensively monitored in European countries to examine its variations and temporal changes (Hötzl et al., 1992; Garland and Pomeroy, 1994; Garger et al., 1997; Müller et al., 2004). Their findings provide essential information for radiation protection and prediction of inhalation dose. However, the applicability of the information to the case of FDNPP accident remains unclear, due to deposition process, land use, meteorological, topographical conditions and the other factors that might affect the resuspension processes. Therefore, it is necessary to accumulate the knowledge of radioactivity in atmospheric aerosol in the area affected by the 
FDNPP accident and compare it with the CNPP accident. Several studies have investigated the dispersion of radiocesium in atmospheric aerosol in eastern Japan following the FDNPP accident (Tsuruta et al., 2014; Igarashi et al., 2015; Ochiai et al., 2016; Kaneyasu et al., 2017). In particular, Kaneyasu et al. (2017) found that the ${ }^{137} \mathrm{Cs}$ concentration reached $10^{-3} \mathrm{~Bq} \mathrm{~m}^{-3}$ orders of magnitude in the city of Tsukuba, Ibaraki Prefecture, up to three months after the accident, whereas Ochiai et al. (2016) reported that one and a half years after the FDNPP accident, the atmospheric ${ }^{137} \mathrm{Cs}$ concentration in the town of Namie, Fukushima Prefecture, ranged from $4.2 \times 10^{-5}-1.1 \times 10^{-3} \mathrm{~Bq} \mathrm{~m}^{-3}$. Tsuruta et al. (2014) also measured the atmospheric ${ }^{134} \mathrm{Cs}$ and ${ }^{137} \mathrm{Cs}$ content in atmospheric aerosol collected on filter tapes in Fukushima city and the Tokyo metropolitan area between 12 and 23 March 2011 to observe their temporal changes. Most of these studies were performed at different sites and focused on relatively early stages of the accident. Kinase et al. (2018) monitored atmospheric ${ }^{137} \mathrm{Cs}$ at four sites affected by the FDNPP accident from 2011 to 2015 and reported their seasonal pattern and resuspension process. However, a decrease in atmospheric ${ }^{137} \mathrm{Cs}$ in the middle and long term more than two years have not been reported.

The resuspension factor $(R F)$ is defined as the ratio of atmospheric radiocesium concentration to the amount of deposition per unit area to estimate the atmospheric radiocesium concentration from the deposition amount. The estimated concentration can be in turn used to estimate the inhalation exposure. Studies conducted after the CNPP accident have demonstrated that the $R F$ value depends on various environmental factors such as wind speed (Garland, 1982; Holländer, 1994), soil conditions (e.g., moisture, roughness, and vegetation) (Gillette, 1978; Wagenpfeil et al., 1999), anthropogenic activities (e.g., car traffic, agricultural operations, decontamination, and cleaning) (Garland and Pomeroy, 1994; Wagenpfeil et al., 1999), and natural events (e.g., wildfire) (Bondarkov et al., 2011). In the case of Fukushima, Yamaguchi et al. (2012) found that the concentration of atmospheric radionuclide increased due to agricultural activities, resulting in an RF value 16 times higher than the background value. Besides, Ochiai et al. (2016) studied the seasonal variation of the atmospheric ${ }^{137} \mathrm{Cs}$ concentration in Namie one and a half years after the FDNPP accident. However, considering the anthropogenic activities, especially decontamination and car traffic, and other environmental conditions, such as wind and weather, differ between the areas affected by the CNPP and FDNPP accidents, there is still a need to clarify the factors affecting the $R F$ in Fukushima.

Recent studies have also suggested that anthropogenic activities can promote reduced air dose rate (Nakama et al., 2019; Saito et al., 2019; Yoshimura et al., 2020), indicating their importance in controlling the radiocesium levels on the ground and their effect on variation and temporal change of the RF. Radiocesium activity was monitored in atmospheric aerosol samples collected at 11 sites for five months after the FDNPP accident as part of a Nuclear Regulation Authority (NRA) project (NRA, 2020). These monitoring sites were located both outside and inside of entryrestricted zone (ERZ), where all activities other than emergency monitoring were restricted due to a high level of contamination. Since anthropogenic activities such as traffic, decontamination and cultivation differed significantly between the outside and inside of ERZ, the data set provided an assessment of the anthropogenic influence on the temporal trend of $R F$.

To assess the atmospheric radiocesium levels and the characteristics of the $R F$ temporal decrease for longer periods, we analyzed the atmospheric aerosol monitoring data obtained at 11 sites in the first seven years after the FDNPP accident. Additionally, anthropogenic impact on the time dependence of $R F$ and differences in the time dependence of the Chernobyl case has been studied.

\section{MATERIALS AND METHODS}

\subsection{Sample Collection and Analysis Method}

Fig. 1 shows the location of monitoring sites. After the FDNPP accident, the area within a radius of $20 \mathrm{~km}$ from the accident site, which is the possible place of a radiation dose exceeded $20 \mathrm{mSv} \mathrm{v}^{-1}$, was designated as the evacuation order zone (EOZ) in which entry was restricted. The atmospheric aerosol was collected at five locations (I-1, I-2, I-3, I-4, and I-5) within the zone from August 2011 to April 2013. After April 2013, the EOZ was divided into three zones: the difficult-to-return zone (DRZ), restricted residence zone, and evacuation order cancellation preparation zone. The entry 


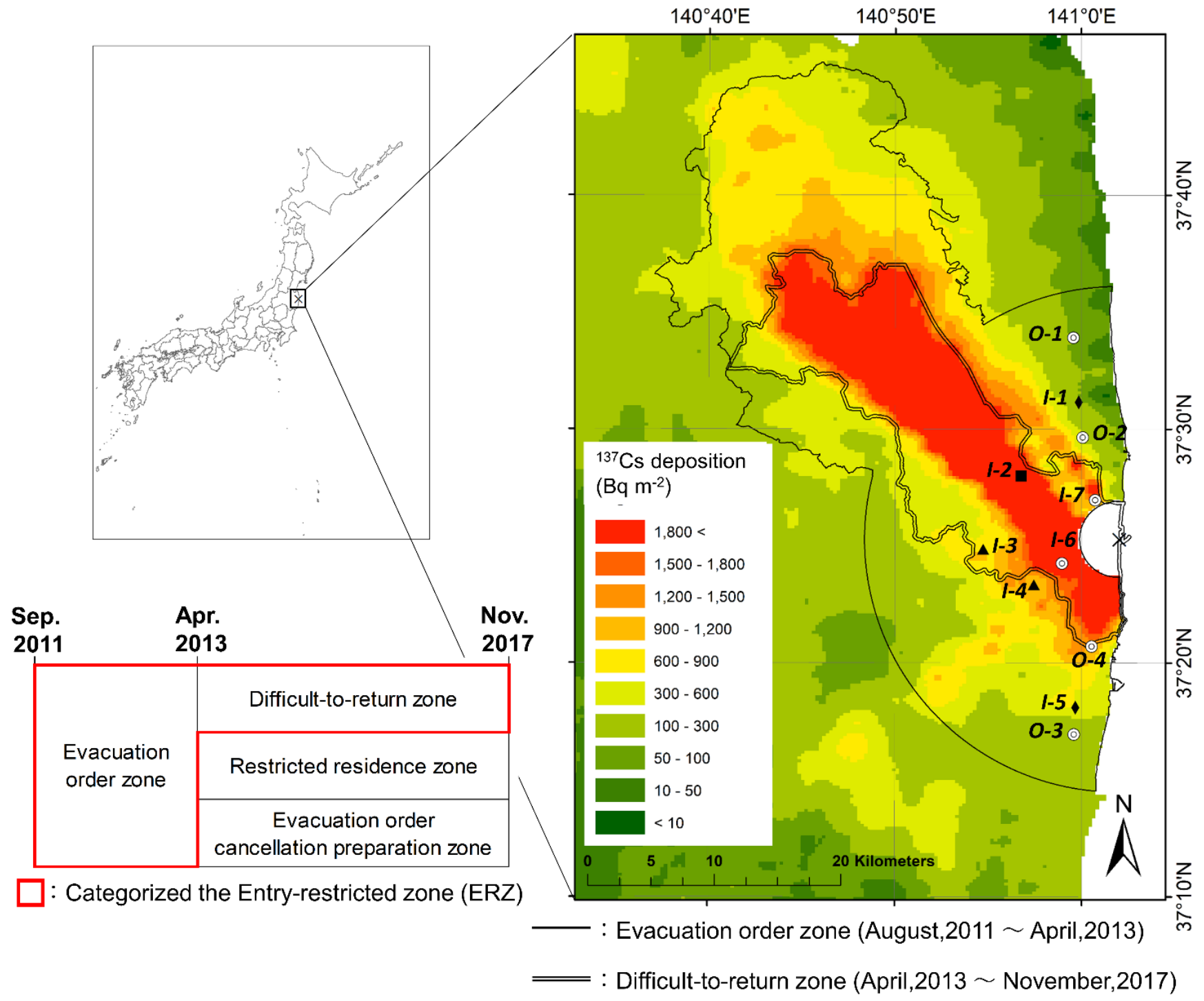

Fig. 1. Distribution map of radiocesium $\left({ }^{137} \mathrm{Cs}\right)$ deposition created by the third airborne monitoring survey data conducted by MEXT obtained in July 2011. The black symbol was the study site monitored during August 2011-April 2013. The white symbol was the study site monitored during April 2013-November 2017. Land use classification: urban (circle), forest (triangle), grassland (square), rice paddy (diamond).

in the DRZ was restricted as well as EOZ, but the entry in the other two zones was allowed. The monitoring sites from May 2013 to November 2017 were changed to two locations (I-6 and I-7) inside the ERZ and four locations (O-1, O-2, O-3, and O-4) outside the ERZ, respectively. Hence, the monitoring sites were classified into two groups; the first was called "inside ERZ," including seven sites located in both EOZ and DRZ, and the second was called "outside ERZ," including the four sites in the other zones. Table 1 summarizes the description of monitoring sites. Land used at these monitoring sites from August 2011 to April 2013 included paddy fields, grassland, and forests whereas only urban areas were used from May 2013 to November 2017.

The atmospheric aerosol samples were collected from August 2011 to April 2013 on glass fiber filters ( $\Phi 60$ mm, HE-40TA; Advantec Co., Ltd.) using a low-volume air sampler (TH-D5199; Chiyoda Technol Corp.) placed approximately $1.1 \mathrm{~m}$ above the ground surface. The collection efficiency of the glass fiber filters was $99 \%$ for the atmospheric aerosol particle size $(0.3 \mu \mathrm{m})$. The samples were regularly collected for $0.5-1 \mathrm{~h}$ with a flow rate of 33-70 $\mathrm{L} \mathrm{min}^{-1}$ monthly. In some cases, two or three samplings were performed per month. In contrast, the atmospheric aerosol samples were collected from May 2013 to November 2017 on glass fiber filters ( $\Phi 110$ mm, GB-100R; Advantec Co., Ltd.) using a high-volume air sampler (HV-1000R; Sibata Scientific Technology Ltd.) 
Table 1. Information about study sites.

\begin{tabular}{|c|c|c|c|c|}
\hline $\begin{array}{l}\text { Inside or outside ERZ } \\
\text { Site }\end{array}$ & Direction from FDNPP & $\begin{array}{l}\text { Distance from FDNPP } \\
(\mathrm{km})^{\mathrm{a}}\end{array}$ & Land use ${ }^{b}$ & 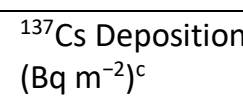 \\
\hline \multicolumn{5}{|l|}{ Inside } \\
\hline $\mathrm{I}-1$ & NNW & 11 & rice paddy & $1.1 \times 10^{5}$ \\
\hline $1-2$ & WNW & 9.2 & grassland & $4.1 \times 10^{6}$ \\
\hline $1-3$ & w & 11 & forest & $8.3 \times 10^{5}$ \\
\hline |-4 & WSW & 7.6 & forest & $9.4 \times 10^{5}$ \\
\hline $1-5$ & SSW & 14 & rice paddy & $4.7 \times 10^{5}$ \\
\hline $1-6$ & WSW & 4.8 & urban & $2.7 \times 10^{6}$ \\
\hline $1-7$ & NNW & 3.5 & urban & $1.2 \times 10^{6}$ \\
\hline \multicolumn{5}{|l|}{ Outside } \\
\hline 0-1 & NNW & 16 & urban & $9.2 \times 10^{4}$ \\
\hline $0-2$ & NNW & 8.5 & urban & $3.0 \times 10^{5}$ \\
\hline $0-3$ & SSW & 16 & urban & $1.9 \times 10^{5}$ \\
\hline $0-4$ & sSW & 8.7 & urban & $1.1 \times 10^{6}$ \\
\hline
\end{tabular}

${ }^{a}$ Direct distance measured.

$\mathrm{b}$ "Land use" is under the sampling point.

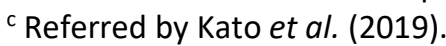

placed approximately $1.25 \mathrm{~m}$ above the ground surface. The collection efficiency of the glass fiber filters was $99.99 \%$ for the atmospheric aerosol particle size of $0.3 \mu \mathrm{m}$. Moreover, atmospheric aerosol was regularly collected from May 2013 to March 2016 for $24 \mathrm{~h}$ with a flow rate of $800 \mathrm{~L} \mathrm{~min}^{-1}$. The collection time was then extended to $48 \mathrm{~h}$ until November 2017 . However, the atmospheric aerosol samples at the I-7 monitoring site were collected only for $6 \mathrm{~h}$, as this site was powered by a generator, which could only operate during daylight.

The collected filter samples were then weighed and compressed into a cylindrical polystyrene bottle (U8: $\Phi 55 \mathrm{~mm} \times 6.8 \mathrm{~cm}$ height, Sekiya Rika Co., Ltd., Tokyo, Japan). The weight of atmospheric aerosol particles was calculated from the weight difference between the filters before and after sampling. The activity concentrations of ${ }^{137} \mathrm{Cs}(661.6 \mathrm{keV})$ in the samples collected during the initial period 2012-2013 and after 2016 were determined using a $\gamma$ spectrometer equipped with a multi-channel analyzer (GSW275L coupled to DSA-1000; Seiko EG\&G ORTEC, Japan). Furthermore, the activity concentrations of ${ }^{137} \mathrm{Cs}$ in the samples collected during the 2013-2016 were determined by a $\gamma$ spectrometer equipped with a multi-channel analyzer (GC3018 CC-HI-U coupled to Lynx DSA; Mirion Technologies [Canberra], Inc.). A multiple- $\gamma$-ray-emitting standard source, including nine nuclides (Japan Radioisotope Association, Japan), was used to calibrate the efficiency. The

${ }^{137} \mathrm{Cs}$ activity concentrations in all samples were decay-corrected to the sampling date.

\subsection{Data Analysis}

The $R F\left(\mathrm{~m}^{-1}\right)$ is the ratio of atmospheric ${ }^{137} \mathrm{Cs}$ concentration $\left(\mathrm{Bq} \mathrm{m}^{-3}\right)$ and initial radiocesium deposition ( $D ; \mathrm{Bq} \mathrm{m}^{-2}$ ) (IAEA, 2010). The $D$ value was estimated from a distribution map of the ${ }^{137}$ Cs deposition established by Kato et al. (2019) based on the airborne monitoring surveys conducted by Ministry of Education, Culture, Sports, Science and Technology (MEXT) and was considered to be the $D$ value in July 2011. The atmospheric aerosol derives from the monitoring site and the surrounding fields; thus, the spatial resolution of the map with $250 \times 250 \mathrm{~m}$ mesh is considered to be more reasonable than the in-situ measurement of ${ }^{137} \mathrm{Cs}$ deposition by soil sampling or portable spectrometer. Table 2 presents the initial ${ }^{137} \mathrm{Cs}$ depositions estimated at each monitoring site of the present study.

The time dependence of the $R F$ in the first $2-5$ years after the FDNPP accident was modeled based on the study reported after the CNPP accident, where the time dependence of the RF was represented by exponential models (Lange et al., 1995; Müller et al., 2004). Here, the data were fitted to the formulas of a single-component and a multi-component exponential model. Since the single-component exponential model showed a smaller mean-square error, it was applied as follows: 
Table 2. Descriptions of sampling and detection limit of ${ }^{137} \mathrm{Cs}$ measurement.

\begin{tabular}{|c|c|c|c|c|c|c|c|}
\hline \multirow{2}{*}{ Site } & \multicolumn{2}{|c|}{ Period } & \multirow{2}{*}{$\begin{array}{l}\text { Sampling interval } \\
\text { (times/month) }\end{array}$} & \multirow{2}{*}{$\begin{array}{l}\text { Data Number } \\
\text { (ND) }\end{array}$} & \multirow{2}{*}{$\begin{array}{l}\text { Sampling time } \\
\text { (hour) }\end{array}$} & \multirow{2}{*}{$\begin{array}{l}\text { Air sampling rate } \\
\left(\mathrm{L} \mathrm{min}^{-1}\right)\end{array}$} & \multirow{2}{*}{ 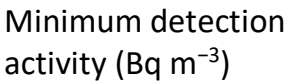 } \\
\hline & Start & Stop & & & & & \\
\hline $\mathrm{I}-1$ & Aug. 2011 & Apr. 2013 & $1-3$ & $5(33)$ & $0.5-1$ & $33-70$ & $1.0 \times 10^{-1}$ \\
\hline I-2 & Aug. 2011 & Apr. 2013 & $1-3$ & $4(34)$ & $0.5-1$ & $33-70$ & $6.0 \times 10^{-1}$ \\
\hline I-3 & Aug. 2011 & Apr. 2013 & $1-3$ & $5(33)$ & $0.5-1$ & $33-70$ & $1.0 \times 10^{-1}$ \\
\hline $1-4$ & Aug. 2011 & Apr. 2013 & $1-3$ & $4(33)$ & $0.5-1$ & $33-70$ & $1.0 \times 10^{-1}$ \\
\hline $1-5$ & Aug. 2011 & Apr. 2013 & $1-3$ & $5(33)$ & $0.5-1$ & $33-70$ & $5.0 \times 10^{-1}$ \\
\hline \multirow[t]{2}{*}{$1-6$} & Apr. 2013 & Mar. 2016 & $1-3$ & $62(14)$ & 24 & 800 & $1.8 \times 10^{-4}$ \\
\hline & Apr. 2016 & Nov. 2017 & 1 & $20(-)$ & 48 & 800 & $1.1 \times 10^{-4}$ \\
\hline I-7 & Apr. 2013 & Nov. 2017 & 1 & $38(15)$ & 6 & 800 & $2.2 \times 10^{-4}$ \\
\hline \multirow[t]{2}{*}{$0-1$} & Apr. 2013 & Mar. 2016 & $1-3$ & $30(46)$ & 24 & 800 & $1.9 \times 10^{-4}$ \\
\hline & Apr. 2016 & Nov. 2017 & 1 & $19(1)$ & 48 & 800 & $4.2 \times 10^{-5}$ \\
\hline \multirow[t]{2}{*}{$0-2$} & Apr. 2013 & Mar. 2016 & $1-3$ & $49(27)$ & 24 & 800 & $1.6 \times 10^{-4}$ \\
\hline & Apr. 2016 & Nov. 2017 & 1 & $20(-)$ & 48 & 800 & $3.7 \times 10^{-5}$ \\
\hline \multirow[t]{2}{*}{$0-3$} & Apr. 2013 & Mar. 2016 & $1-3$ & $20(56)$ & 24 & 800 & $2.0 \times 10^{-4}$ \\
\hline & Apr. 2016 & Nov. 2017 & 1 & $20(-)$ & 48 & 800 & $3.1 \times 10^{-5}$ \\
\hline \multirow[t]{2}{*}{$0-4$} & Apr. 2013 & Mar. 2016 & $1-3$ & $65(11)$ & 24 & 800 & $1.9 \times 10^{-4}$ \\
\hline & Apr. 2016 & Nov. 2017 & 1 & $20(-)$ & 48 & 800 & $1.1 \times 10^{-4}$ \\
\hline
\end{tabular}

$K(t)=K_{0} \cdot \exp \left(-\frac{\ln 2}{T} t\right)+K_{1}$

where $K(t)$ refers to the $R F$ at time $t\left(\mathrm{~m}^{-1}\right) ; K_{0}$ is a constant representing the initial $R F$ value $\left(\mathrm{m}^{-1}\right)$ after the accident; $K_{1}$ is the long-term $R F\left(\mathrm{~m}^{-1}\right) ; T$ is the effective half-life; $t$ represents the time after deposition in years.

\section{RESULTS AND DISCUSSION}

\subsection{Atmospheric ${ }^{137}$ Cs Concentration}

Fig. 2 shows a temporal change in atmospheric ${ }^{137} \mathrm{Cs}$ concentration observed at the inside and outside ERZ. The majority of data, accounting for $88 \%$ of the total samples from August 2011 to April 2013, was not detected due to the short analysis time of the $\gamma$ spectrometer and the short collection time of the atmospheric aerosol samples. Thus, the data observed (I-1-I-4) in Fig. 2(a) were only the top $12 \%$ values presented as reference. In contrast, all samples were above the detection limit after May 2013 due to the extension of the collection time of atmospheric aerosol and measurement time by the Ge detector. Moreover, the atmospheric ${ }^{137} \mathrm{Cs}$ concentration decreased over time throughout the monitoring period. Specifically, atmospheric ${ }^{137} \mathrm{Cs}$ concentrations ranged from $10^{-1}-10^{0} \mathrm{~Bq} \mathrm{~m}^{-3}$ until April 2013, followed by ranges $10^{-4}-10^{-1}$ and $10^{-5}-10^{-1} \mathrm{~Bq} \mathrm{~m}^{-3}$ inside and outside ERZ, respectively. Notably, the ${ }^{137} \mathrm{Cs}$ concentration at sites $0-1-0-3$ was significantly reduced after the first five years (Fig. 2(b)), possibly due to anthropogenic activities such as decontamination processes around the monitoring sites (Ministry of the Environment, Japan, 2013).

\subsection{RF of Atmospheric ${ }^{137} \mathrm{Cs}$}

The temporal changes in the $R F$ of atmospheric ${ }^{137} \mathrm{Cs}$ were also investigated inside and outside the Fukushima ERZ to examine its effect on the atmospheric ${ }^{137} \mathrm{Cs}$ concentration. Fig. 2 depicts that temporal change in $R F$ observed at the inside and outside ERZ. The $R F$ values inside ERZ from August 2011 to April 2013 ranged from $1.5 \times 10^{-7}$ to $8.0 \times 10^{-6} \mathrm{~m}^{-1}$, as shown in Fig. 3(a). Similar to the atmospheric ${ }^{137} \mathrm{Cs}$ concentrations, the $R F$ values were also biased due to the high detection limit and short collection time of the atmospheric aerosol samples. In contrast, 2-5 years after the FDNPP accident, the RF values inside and outside ERZ were significantly lower than the initial two years, ranging from $6.7 \times 10^{-11}-2.8 \times 10^{-8} \mathrm{~m}^{-1}$ and $1.7 \times 10^{-10}-2.0 \times 10^{-7} \mathrm{~m}^{-1}$, respectively. 

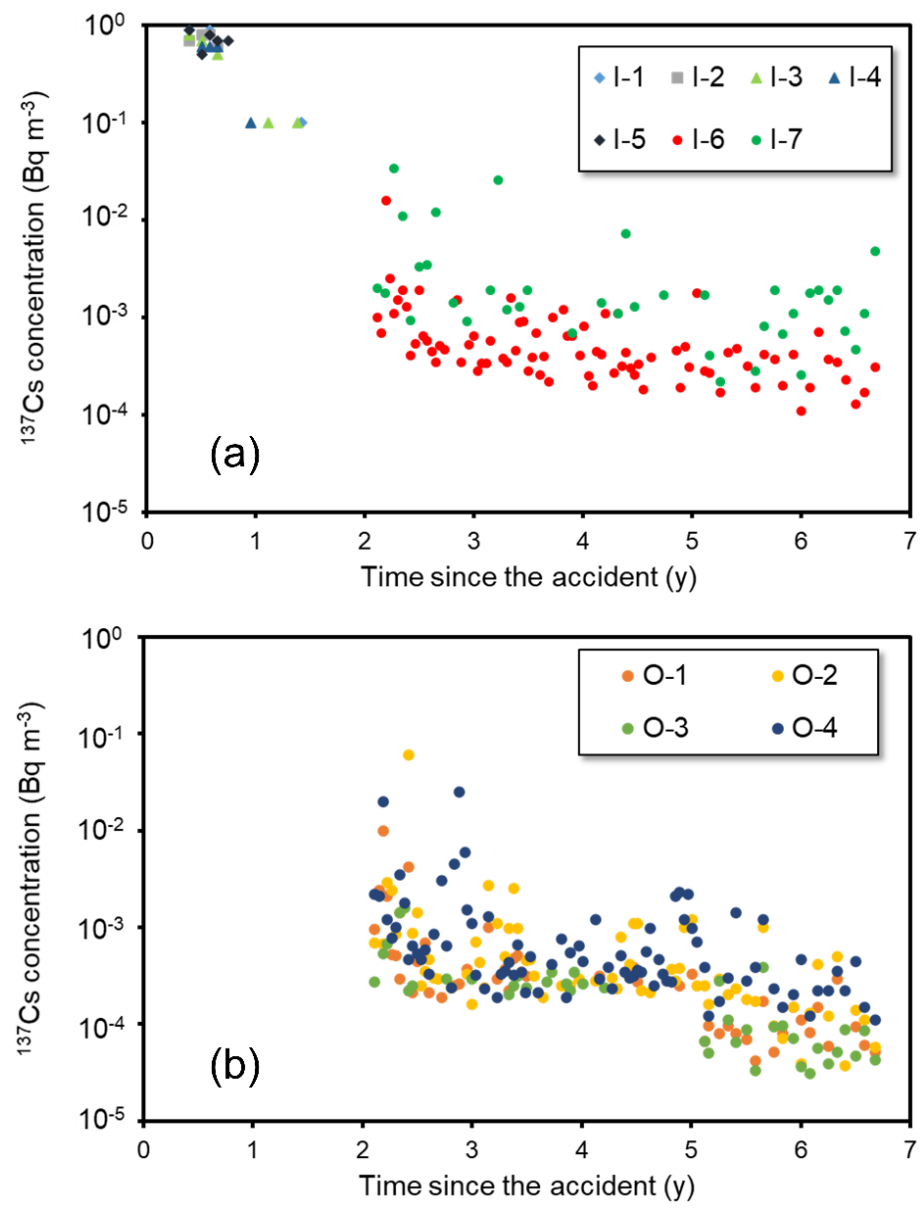

Fig. 2. Temporal change in atmospheric ${ }^{137} \mathrm{Cs}$ concentration observed (a) inside and (b) outside the ERZ. Land use classification: urban (circle), forest (triangle), grassland (square), rice paddy (diamond).

$R F$ varied one order of magnitude depending on the site and whether the site is inside or outside ERZ. Ochiai et al. (2016) reported $R F$ values $\left(5.7 \times 10^{-11}-8.6 \times 10^{-10} \mathrm{~m}^{-1}\right)$ in Namie $1.5-2.5$ years after the accident, which are lower than the values observed in this study 2-5 years after the accident, showing a large site-dependency of $R F$, although difficult to explain the difference in $R F$ among sites.

Furthermore, after the first five years of the accident, the $R F$ values outside ERZ were further reduced $\left(1.0 \times 10^{-10}-4.0 \times 10^{-9} \mathrm{~m}^{-1}\right)$, especially at the study sites $0-1,0-2$, and $0-3(\mathrm{Fig} .3(\mathrm{~b}))$, where anthropogenic activities were inferred. Besides, the yearly average values in the first 4-5, 5-6, and 6-7 years after the accident were $2.1 \times 10^{-9}, 9.8 \times 10^{-10}$, and $7.1 \times 10^{-10} \mathrm{~m}^{-1}$, respectively, suggesting that anthropogenic activities possibly reduce the $R F$ by half during these three years.

\subsection{RF Time Dependence}

The $R F$ showed a slow decay after two years of the FDNPP accident based on the findings discussed in the previous section (Fig. 3). To accurately determine the decreasing rate of $R F$, Eq. (1) was used for the data obtained only in the first 2-5 years due to uncertainties arising from the poor quality of data collected during the initial period and the anthropogenic effect observed five years after the accident. Furthermore, the variation in RF showed log-normal distribution; Eq. (1) was fitted to the geometric mean value of the $R F$ every $0.5 \mathrm{y}$. Finally, the obtained models for the sites inside and outside ERZ could be expressed using Eqs. (2) and (3), respectively as follows:

$K(t)=1.70 \times 10^{-7} \cdot \exp \left(-\frac{\ln 2}{0.29} t\right)+2.26 \times 10^{-10}$ 

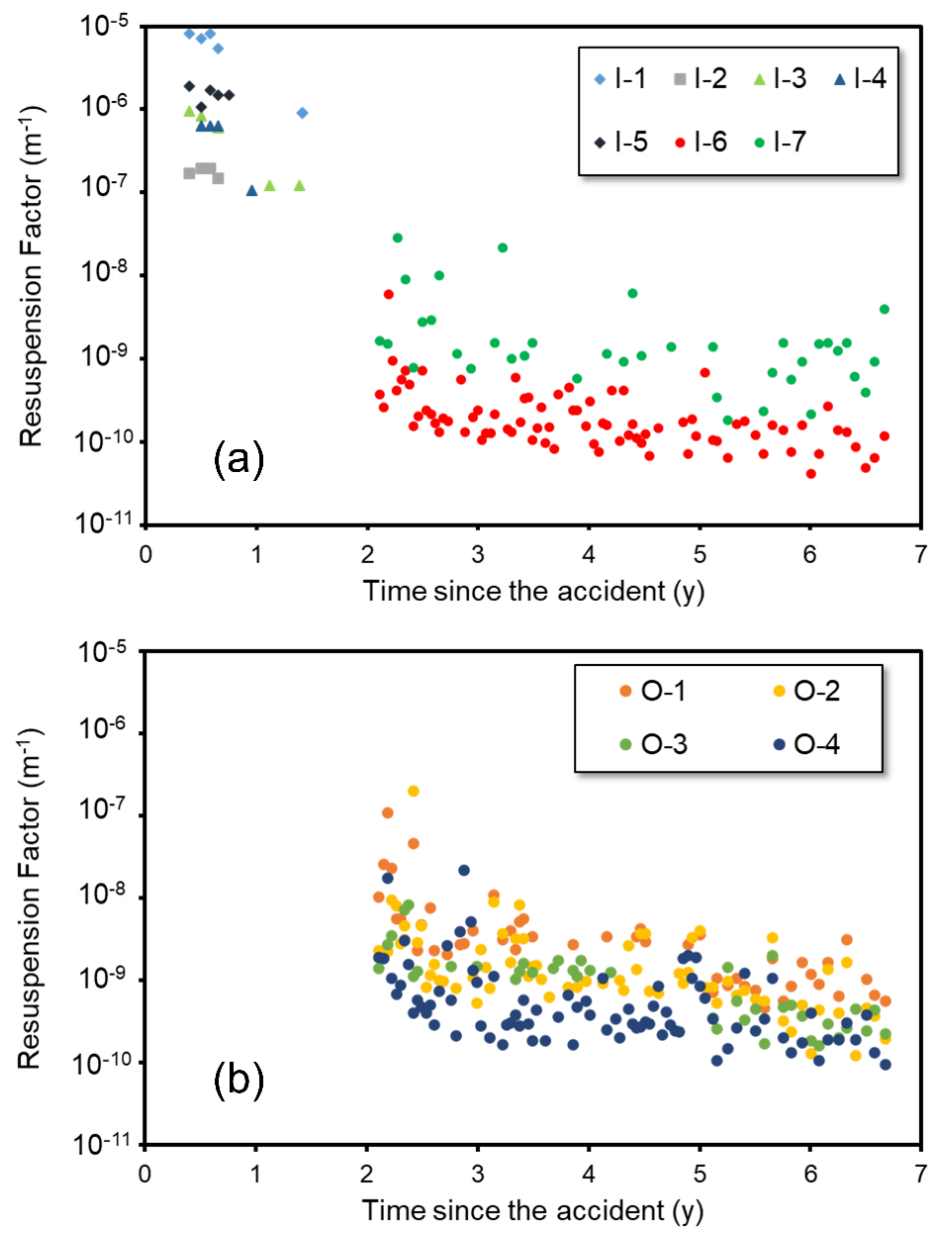

Fig. 3. Temporal change in RF observed (a) inside and (b) outside the ERZ. Land use classification: urban (circle), forest (triangle), grassland (square), rice paddy (diamond).

$K(t)=4.14 \times 10^{-6} \cdot \exp \left(-\frac{\ln 2}{0.22} t\right)+8.86 \times 10^{-10}$

where $K(t)$ is the $R F\left(\mathrm{~m}^{-1}\right)$ at time $t(\mathrm{y}) ; t$ represents the time after deposition in years.

The changes in the RF over time inside and outside ERZ during that period (2-5 y) can be estimated, as shown in Fig. 4. In particular, we found that the effective half-life outside ERZ (0.22 y) was shorter than that inside the zone $(0.29$ y). Moreover, based on recent studies, the air dose rate outside ERZ decreased faster than inside ERZ, whereas the reduction was considered to be facilitated by anthropogenic activities (Nakama et al., 2019; Saito et al., 2019; Yoshimura et al., 2020). Therefore, anthropogenic activities may promote environmental remediation including atmospheric radiocesium concentration, suggesting that the anthropogenic activities possibly reduce the risk of inhalation radiation in the future.

\subsection{Comparison of Fitting Data between the CNPP and FDNPP Accidents}

Fig. 5 shows a temporal decrease in the $R F$ values for all sites (i.e., sites inside and outside ERZ) measured in this study and also compared with the results reported for the CNPP accident in which a power function model (Hötzl et al., 1992; Garland et al., 1994; Garger et al., 1997) and a single-component exponential model (Eq. (1)) (Müller et al., 2004) and multi-component exponential model (Lange et al., 1995) were applied. The exponential functions fitted to our results in Fukushima all sites had an effective half-life of $0.19 \mathrm{y}$. This value is smaller than that reported by Müller et al. (2004) after the Chernobyl accident, probably due to the different environmental fate of radiocesium between Fukushima and Chernobyl as described below. 


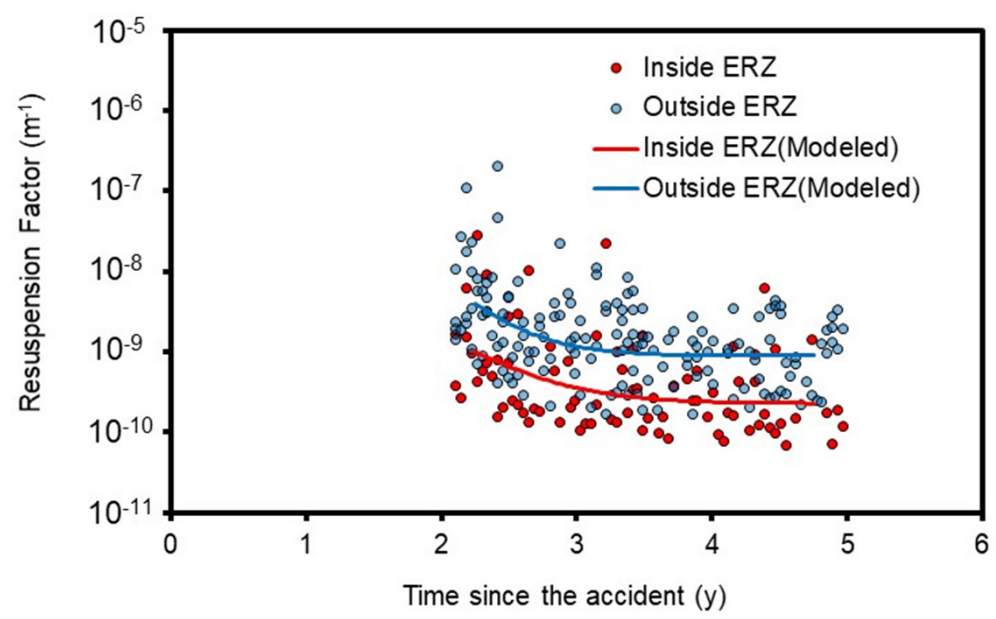

Fig. 4. Time dependence of the RF 2-5 years after the FDNPP accident. The solid lines show the fitting result for the $R F$ data obtained during the period in Eq. (1). The red and blue solid lines show the fitting result for the data obtained inside and outside the ERZ, respectively.

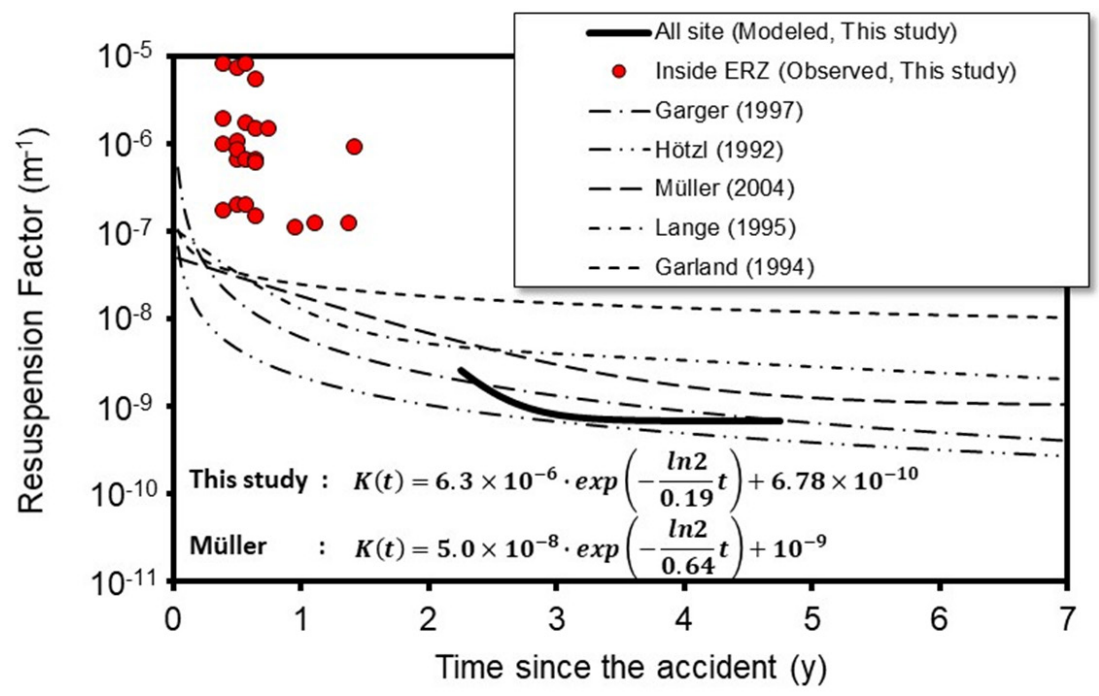

Fig. 5. Comparison of the $R F$ temporal decrease modeled in this study Fukushima all sites (black line) with the results of earlier studies obtained after the CNPP accident (dashed lines). The red points represent the $R F$ values obtained for the Fukushima ERZ up to two years after the FDNPP accident.

Konoplev et al. (2016) also reported that the vertical migration of radiocesium in grassland soil was faster in Fukushima than in the area affected by the CNPP accident due to higher annual precipitation. This probably led to a faster decrease in radiocesium activity at the surface ground in Fukushima, resulting in a faster decrease in the activity of resuspended matter. Furthermore, Onda et al. (2020) found that higher precipitation, steeper topography, and anthropogenic activities in the Fukushima area have led to a greater hydrological uptake of radiocesium, facilitating the environmental remediation at the catchment scale. Mostly, land uses relating to anthropogenic activities such as agricultural and paddy fields facilitated radiocesium wash-off. These faster environmental remediations were probably reflected in the faster $R F$ reduction observed in this study. However, Saito et al. (2019) reported a slower vertical migration of radiocesium in Fukushima. This discrepancy may be due to differences in the field of study, as Konoplev et al. (2016) and Onda et al. (2020) have targeted large areas, such as catchments, including anthropogenic influences. In contrast, Saito et al. (2019) analyzed the data obtained from flat and open fields without considering the effect of human activities. The large-scale remediation observed in the present study may reflect the increasing reduction rate of $R F$ as atmospheric aerosol derives from a wide area. 
$R F$ ranges were similar to those derived from the power function models reported approximately five years after the CNPP accident (Hötzl et al., 1992; Garger et al., 1997); however, the decreasing rate of $R F$ was higher than that obtained from the CNPP case. These results suggest that the longterm inhalation exposure in Fukushima is lower than estimated by the models reported after the CNPP accident if the initial deposition amounts are the same. Furthermore, the present study could not evaluate the RF during the first two years after the FDNPP accident, which could significantly affect the initial internal exposure (WHO, 2013), with a significant temporal decrease in atmospheric radiocesium concentrations for medium to long periods after the accident. The present data are expected to be useful, particularly in the future for estimating additional exposure to radiocesium.

\section{CONCLUSIONS}

This study evaluates the temporal change in the atmospheric radiocesium concentration and $R F$ over the first seven years following the FDNPP accident. Our observations revealed that the radiocesium concentration exhibited a range of $10^{-1}-10^{0} \mathrm{~Bq} \mathrm{~m}^{-3}$ during the first two years and then decreased to $10^{-5}-10^{-1} \mathrm{~Bq} \mathrm{~m}^{-3}$ over the next five years, whereas the $R F$ inside and outside of the ERZ varied from $6.7 \times 10^{-11}$ to $2.8 \times 10^{-8} \mathrm{~m}^{-1}$ and from $1.7 \times 10^{-10}$ to $2.0 \times 10^{-7} \mathrm{~m}^{-1}$, respectively, between two and five years after the accident. Notably, the effective half-life was shorter outside than inside the ERZ, indicating that anthropogenic activities greatly facilitate the remediation of a radiocesium-contaminated atmosphere. Furthermore, we measured a faster $R F$ decay than the one reported for the CNPP accident.

\section{ACKNOWLEDGMENTS}

Special thanks are due to our colleagues of the Fukushima Remote Monitoring Group and Research, Japan Atomic Energy Agency.

\section{DISCLAIMER}

The authors decline any commercial link with the companies producing equipment or software used in this study.

\section{REFERENCES}

Bondarkov, M.D., Oskolkov, B.Y., Gaschak, S.P., Kireev, S.I., Maksimenko, A.M., Proskura, N.I., Jannik, G.T., Farfán, E.B. (2011). Environmental radiation monitoring in the Chernobyl Exclusion Zone-history and results 25 years after. Health Phys. 101, 442-485. https://doi.org/10.1097/ hp.0b013e318229df28

Garger, E.K., Hoffman, F.O., Thiessen, K.M. (1997). Uncertainty of the long-term resuspension factor. Atmos. Environ. 31, 1647-1656. https://doi.org/10.1016/S1352-2310(96)00345-7

Garland, J.A. (1982). Resuspension of particulate matter from grass. Experimental Programme 19791980. AERE Report - R 10106, London HMSO. https://doi.org/10.1016/0021-8502(94)90047-7

Garland, J.A., Pomeroy, I.R. (1994). Resuspension of fall-out material following the Chernobyl accident. J. Aerosol Sci. 25, 793-806. https://doi.org/10.1016/0021-8502(94)90047-7

Gillette. D.A. (1978). A wind tunnel simulation of the erosion of soil: Effects on soil texture, sandblasting, wind speed and soil consolidation on dust production. Atmos. Environ. 12, 17351743. https://doi.org/10.1016/0004-6981(78)90322-0

Holländer, W. (1994). Resuspension factors of ${ }^{137} \mathrm{Cs}$ in Hannover after the Chernobyl accident. J. Aerosol Sci. 25, 789-792. https://doi.org/10.1016/0021-8502(94)90046-9

Hötzl, H., Rosner, G., Winkler, R. (1992). Sources of present Chernobyl-derived caesium concentrations in surface air and deposition samples. Sci. Total Environ. 119, 231-242. https://doi.org/10.101 6/0048-9697(92)90266-U

Igarashi, Y., Kajino, M., Zaizen, Y., Adachi, K., Mikami, M. (2015). Atmospheric radioactivity over 
Tsukuba, Japan: A summary of three years of observations after the FDNPP accident. Prog. Earth Planet. Sci. 2, 44. https://doi.org/10.1186/s40645-015-0066-1

International Atomic Energy Agency (IAEA) (2010). Handbook of Parameter Values for the Prediction of Radionuclide Transfer in Terrestrial and Freshwater Environments, Technical reports series no. 472.

International Atomic Energy Agency (IAEA) (2013). Actions to Protect the Public in an Emergency due to Severe Conditions at a Light Water Reactor, EPR-NPP Public Protective Action.

Kaneyasu, N., Ohashi, H., Suzuki, F., Okuda, T., Ikemori, F., Akata, N., Kogure, T. (2017). Weak size dependence of resuspended radiocesium adsorbed on soil particles collected after the Fukushima nuclear accident. J. Environ. Radioact. 172, 122-129. https://doi.org/10.1016/j.jen vrad.2017.03.001

Kato, H., Onda, Y., Gao, X., Sanada, Y., Saito, K. (2019). Reconstruction of a Fukushima accidentderived radiocesium fallout map for environmental transfer studies. J. Environ. Radioact. 210, 105996. https://doi.org/10.1016/j.jenvrad.2019.105996

Kinase, T., Kita, K., Igarashi, Y., Adachi, K., Ninomiya, K., Shinohara, A., Okochi, H., Ogata, H., Ishizuka, M., Toyoda, S., Yamada, K., Yoshida, N., Zaizen, Y., Mikami, M., Demizu, H., Onda, Y. (2018). The seasonal variations of atmospheric ${ }^{134,137} \mathrm{Cs}$ activity and possible host particles for their resuspension in the contaminated areas of Tsushima and Yamakiya, Fukushima, Japan. Prog. Earth Planet. Sci. 5, 12. https://doi.org/10.1186/s40645-018-0171-z

Konoplev, A., Golosov, V., Laptev, G., Nanba, K., Onda, Y., Takase, T., Wakiyama, Y., Yoshimura, K. (2016). Behavior of accidentally released radiocesium in soil-water environment: Looking at Fukushima from a Chernobyl perspective. J. Environ. Radioact. 151, 568-578. https://doi.org/1 0.1016/j.jenvrad.2015.06.019

Lange, C., Roed, J., Zombori, P., Fehèr, I., Paretzke, H., Tschiersch, J., Rybàcek, K., Tomàsek, M., Navarcik, I., Jansta, V., Dstelinka, I., Cipakova, A. (1995) Resuspension of deposited material (Chapter 6 of the CEC report). Deposition of Radionuclides, their Subsequent Relocation in the Environment and Resulting Implications, EUR 1664 EN, ISBN 92-827-4903-7.

Ministry of the Environment Japan. (2013). Decontamination Guidelines 2nd Ed., 2013 (TentativeTranslation). http://josen.env.go.jp/en/policy_document/pdf/decontamination_gu idelines_2nd.pdf (accessed 14 December 2018).

Müller, H., Gering, F., Pröhl, G. (2004). Model description of the Terrestrial Food Chain and Dose Module FDMT in RODOS PV6.0. RODOS(RA3)-TN(03)06. 03, 57.

Nakama, S., Yoshimura, K., Fujiwara, K., Ishikawa, H., lijima, K. (2019). Temporal decrease in air dose rate in the sub-urban area affected by the Fukushima Dai-ichi Nuclear Power Plant accident during four years after decontamination works. J. Environ. Radioact. 208-209, 106013. https://doi.org/10.1016/j.jenvrad.2019.106013

Nuclear Regulation Authority (NRA) (2020). Reading of Land Monitoring. https://radioactivity.nsr. go.jp/en/list/313/list-1.html (accessed 1 September 2020).

Ochiai, S., Hasegawa, H., Kakiuchi, H., Akata, N., Ueda, S., Tokonami, S., Hisamatsu, S. (2016). Temporal variation of post-accident atmospheric ${ }^{137} \mathrm{Cs}$ in an evacuated area of Fukushima Prefecture: Size-dependent behaviors of ${ }^{137}$ Cs-bearing particles. J. Environ. Radioact. 165, 131139. https://doi.org/10.1016/j.jenvrad.2016.09.014

Onda, Y., Taniguchi, K., Yoshimura, K., Kato, H., Takahashi, J., Wakiyama, Y., Coppin, F., Smith, H. (2020). Radionuclides from the Fukushima Daiichi Nuclear Power Plant in terrestrial systems. Nat. Rev. Earth Environ. 12, 644-660. https://doi.org/10.1038/s43017-020-0099-x

Saito, K., Mikami, S., Andoh, M., Matsuda, N., Kinase, S., Tsuda, S., Yoshida, T., Sato, T., Seki, A., Yamamoto, H., Sanada, Y., Wainwright-Murakami, H., Takemiya, H. (2019). Summary of temporal changes in air dose rates and radionuclide deposition densities in the $80 \mathrm{~km}$ zone over five years after the Fukushima Nuclear Power Plant accident. J. Environ. Radioact. 210, 105878. https://doi.org/10.1016/j.jenvrad.2018.12.020

Tsuruta, H., Oura, Y., Ebihara, M., Ohara, T., Nakajima, T. (2014). First retrieval of hourly atmospheric radionuclides just after the Fukushima accident by analyzing filter-tapes of operational air pollution monitoring stations. Sci. Rep. 4, 6717. https://doi.org/10.1038/srep06717

Wagenpfeil, F., Paretzke, H.G., Peres, J.M., Tschiersch, J. (1999). Resuspension of coarse particles in the region of Chernobyl. Atmos. Environ. 33, 3313-3323. https://doi.org/10.1016/S13522310(98)00293-3 
World Health Organization (WHO) (2012). Preliminary dose estimation from the nuclear accident after the 2011 Great East Japan Earthquake and Tsunami. https://www.who.int/publications/ i/item/9789241503662 (accessed 20 August 2020).

World Health Organization (WHO) (2013). Health risk assessment from the nuclear accident after the 2011 Great East Japan Earthquake and Tsunami. https://www.who.int/publications/i/item/ 9789241505130 (accessed 20 August 2020).

Yamaguchi, N., Eguchi, S., Fujiwara, H., Hayashi, K., Tsukada, H. (2012). Radiocesium and radioiodine in soil particles agitated by agricultural practices: Field observation after the Fukushima nuclear accident. Sci. Total Environ. 425, 128-134. https://doi.org/10.1016/j.scitot env.2012.02.037

Yoshimura, K., Saegusa, J., Sanada, Y. (2020). Initial decrease in the ambient dose equivalent rate after the Fukushima accident and its difference from Chernobyl. Sci. Rep. 10, 1-9. https://doi.org/10.1038/s41598-020-60847-0 